\begin{tabular}{|l|l|l|}
\hline \multicolumn{2}{|c|}{ PublisherInfo } \\
\hline \hline PublisherName & $:$ & BioMed Central \\
\hline \hline PublisherLocation & $:$ & London \\
\hline \hline PublisherImprintName & $:$ & BioMed Central \\
\hline \hline
\end{tabular}

\title{
IL-1 receptor antagonist-deficient mice develop autoimmune
} arthritis

\begin{tabular}{|l|l|l||}
\hline \multicolumn{2}{|c|}{ ArticleInfo } \\
\hline \hline ArticleID & $:$ & 14 \\
\hline \hline ArticleDOI & $:$ & $10.1186 /$ ar-2000-66777 \\
\hline \hline ArticleCitationID & $:$ & 66777 \\
\hline \hline ArticleSequenceNumber & $:$ & 10 \\
\hline \hline ArticleCategory & $:$ & Paper Report \\
\hline \hline ArticleFirstPage & $:$ & 1 \\
\hline \hline ArticleLastPage & $:$ & 1 \\
\hline \hline & & RegistrationDate : 2000-1-31 \\
\hline ArticleHistory & $:$ & OnlineDate \\
\hline ArticleCopyright & $:$ & Current Science Ltd2000-1-31 \\
\hline \hline ArticleGrants & $:$ & \\
\hline \hline ArticleContext & $:$ & 130752211 \\
\hline \hline
\end{tabular}




\section{Keywords}

Animal model, cytokine, IL-1 receptor antagonist, rheumatoid arthritis

\section{Context}

Previous studies have suggested that the cytokine IL-1 is central to the development of RA. IL-1 is produced by a variety of cells, including monocytes, macrophages and synovial lining cells. There are three members of the IL-1 family that bind to IL-1 receptors: IL-1 $\hat{I}^{2}$, IL-1 $1 \pm$ and IL-1ra. IL-1ra binds the receptor and prevents binding of IL- $1 \hat{I}^{2}$ or $\hat{I} \pm$, but does not elicit a signalling response. This is a means of regulating the signalling activity of IL-1, with the ratio of IL-1 to IL-1 ra determining the level of IL-1 signalling. IL-1 ra is inducible by other cytokines and its levels are increased in autoimmune and inflammatory diseases, suggesting that it plays a regulatory role in the immune response. To create an IL-1ra-deficient mouse and to demonstrate the central role of IL-1 homeostasis in RA development.

\section{Significant findings}

Although $\mathrm{F}_{1}$ hybrid IL-1ra-deficient mice were normal, chronic inflammatory arthropathy was observed in mice following a five-generation backcross to BALB/cA mice. Histological analysis of the affected joints showed synovial and periarticular inflammation with infiltration of lymphocytes and neutrophils into the synovial space and proliferation of synovial lining cells. Bone erosion was also noted together with osteoclast activation. Both incidence and severity of disease increased with age in male and female IL-1ra-deficient mice, with arthritis initially detected at 5 weeks of age. In contrast to the BALB/cA-derived mice, IL-1ra-deficient mice bred on to a C57BL/6J background did not develop arthritis at 16 weeks, and demonstrated only a low incidence of disease in older animals. Further histological analysis showed that the IL-1 ra-deficient mice had enlarged spleens and lymph nodes; however, FACS analysis of T and B cells showed that these populations were identical in wild-type and deficient mice. Comparison of serum immunoglobulin levels of IL-1ra-/- with wild-type mice showed the deficient mice to have elevated IgE and IgG1 levels at 16 weeks of age, while IgM and IgG2 $\hat{I}^{2}$ and $\mathrm{IgG} 2 \hat{\mathrm{I}} \pm$ levels remained unchanged and the IgG3 level was slightly reduced. Increased levels of autoantibodies against type II collagen, double stranded DNA and IgG rheumatoid factor (RF), but not IgM RF, were found in the IL-ra-/- mice compared to wild-type controls. Levels of autoantibodies did not correlate with disease severity. Increased expression of IL-1 $\mathrm{I} \pm$, IL-6, TNF- ${ }^{2}$, COX-2 and IL-1RI and -RII was observed in the joints of 16 week old IL-1ra-deficient mice. Elevated cytokine levels could also be detected in younger animals before the onset of disease. 


\section{Comments}

This paper clearly underscores the physiological importance of maintaining interleukin (IL)-1 homeostasis: mice deficient in IL-1 receptor antagonist (IL-1 ra) develop arthritis, exhibiting joint pathology and immunological profiles that resemble rheumatoid arthritis in humans, providing a useful animal model of human RA. However, incidence of disease in IL-1 ra-deficient mice is dependent on the strain used, indicating that other genetic factors are involved. This paper highlights the critical influence that the genetic background plays in the development of the disease phenotype. Although not discussed by the authors, the results suggest that use of IL-1 ra could be a valid strategy for the treatment of $R A$.

\section{Methods}

IL-1ra-deficient mice were created by replacing the exon encoding the secreted form of IL-1ra with the neogene by homologous recombination. These mice were then backcrossed onto either BALB/cA or C57BL/6J strain mice. The incidence of arthritis was determined macroscopically; each joint was assessed weekly for swelling and redness and the severity of arthritis was graded. $\mathrm{T}$ and $\mathrm{B}$ cell populations from thymuses, spleen and lymph nodes were characterised using fluorescence-activated cell sorter (FACS) analysis. Serum levels of immunoglobulin (Ig) G, IgM and IgE were measured by ELISA. Cytokine and receptor mRNA expression for IL-1ra, IL-1 $\hat{I}^{2}$, IL-1 $\hat{\mathrm{I}} \pm$, IL-6, tumour necrosis factor (TNF)- $\hat{I}^{2}$, cyclooxygenase (COX)-2 and IL-1 receptors I and II were measured using northern analysis and related to the expression of $\hat{\mathrm{I}} \pm$-actin.

\section{References}

1. Horai R, Saijo S, Tanioka H, Nakae S, Sudo K, Okahara A, Ikuse T, Asano M, Iwakura Y: Development of chronic inflammatory arthropathy resembling rheumatoid arthritis in interleukin 1 receptor antagonist-deficient mice. J Exp Med. 2000, 191: 313-320.

This PDF file was created after publication. 